\title{
Making Public Health Nutrition relevant to evidence-based action: are we doing enough?
}

What is the point of a journal like Public Health Nutrition? My personal view is that the journal should be a forum for the presentation of original research to identify the causes of nutrition-related health problems, to identify what works in promoting the application of that evidence in prevention and promotion, and ultimately to inform and influence policy to improve health.

An important part of this process is the way in which information is gathered and reviewed by government and other agencies to develop, implement and evaluate policy. In this issue of the journal, a group of academics (and I should declare an interest as one of those authors), mainly from the UK, have argued that to date we have largely failed to develop a sufficiently robust evidencebased approach to gathering and reviewing nutrition and health studies ${ }^{1}$.

Nobody would disagree with the need for evidencebased nutrition; the challenge is how to do it properly. The underlying philosophy is openness and transparency. The authors have argued that education and training - at all levels - for nutritionists needs to be improved and reoriented to include skills in critical appraisal and systematic review methodology. While there has been substantial health gain in most countries other than those affected by HIV, wars and social upheaval over the last 30 years, there are still massive inequalities within and between countries and we need to muster all our resources in the most efficient and objective way to identify what does and does not work so that we can implement evidence-based programmes aimed at reducing these inequalities.

In an increasingly competitive environment we have to be able to show that what we do can make a difference, and that it is cost effective. It is no longer sufficient simply to assert that nutrition is important and makes a difference without the evidence to back up this assertion, no matter how difficult it is to do. We must also be able to say when we don't know the answer, and argue for more and better quality research to help provide the answer. Ultimately if we do not make ourselves useful to the needs of government why should they listen to what we have to say, and why should they fund what we do? It is a messy business, but if we do not engage in this, others will, and if we do not like what they come up with, what right will we have to complain about it? If any reader has any views about this let us know.
Also in this issue we report the results of four schoolbased studies, two in South Africa ${ }^{2,3}$, one in the $\mathrm{UK}^{4}$, and one in Germany ${ }^{5}$. The two studies from KwaZulu Natal in South Africa assessed the effectiveness of fortified biscuits $^{2}$ and helminth control ${ }^{3}$. van Stuijvenberg et $a l^{2}$ evaluated the effectiveness of a micronutrient-fortified biscuit. During school time the biscuits were able to maintain micronutrient levels, but these levels fell away when children were not at school. They argued that a longer-term solution such as improving local food production, combined with community development might be more effective. Jinabhai et $a l^{3}$ evaluated the effectiveness of a school-based programme to reduce helminth infections. While they showed significant reductions in infection rate they did not show substantial effects on the prevalence of stunting or wasting.

The UK study ${ }^{4}$ evaluated the effectiveness of multiple interventions at lunchtime to increase the consumption of healthier foods in three secondary schools. After two years of follow up there were no significant changes in schoolbased eating. The authors concluded how difficult it was to achieve sustained dietary changes. The Study in Germany showed that children who spent more time watching television were more likely to have an increased fat mass ${ }^{5}$.

Barrie Margetts

\section{References}

1 Brunner E, Rayner M, Thorogood M, Margetts B, Hooper L, Summerbell C, Hewitt G, Robertson A, Wiseman M, Dowler E. Making Public Health Nutrition relevant to evidencebased action. Public Health Nutr. 2001; 4: 1297-9.

2 van Stuijvenberg ME, Dhansay MA, Smuts CM, Lombard CJ, Jogessar VB, Benade AJS. Long-term evaluation of a micronutrient-fortified biscuit used for addressing micronutrient deficiencies in primary school children. Public Health Nutr. 2001; 4: 1201-9.

3 Jinabhai CC, Taylor M, Coutsoudis A, Coovadia HM, Tomkins AM, Sullivan KR. Epidemiology of helminth infections: implications for parasite control programmes, a South African perspective. Public Health Nutr. 2001; 4: 1211-9.

4 Parker L, Fox A. The Peterborough Schools Nutrition Project: a multiple intervention programme to improve school-based eating in secondary schools. Public Health Nutr. 2001; 4: 1221-8.

5 Grund A, Krause H, Siewers M, Rieckert H, Müller MJ. Is TV viewing an index of physical activity and fitness in overweight and normal weight children? Public Health Nutr. 2001; 4: 1245-51. 